\title{
Cooperativismo y Globalización
}

\author{
Enrique Gadea \\ Universidad de Deusto
}

\begin{abstract}
Sumario: I. Un apunte sobre el concepto de globalización y sobre sus consecuencias en el ámbito económico.- -Il. La Alternativa Cooperativa: una explicación del ideario cooperativo a través de sus principios. - III. La efectividad de la democracia participativa en las cooperativas como elemento clave para el éxito del movimiento.-IV. Inserción social y Cooperativismo.
\end{abstract}

\section{Un apunte sobre el concepto de Globalización y sobre sus consecuencias en el ámbito económico}

La palabra Globalización es muy utilizada en nuestros días, aunque no es fácil formular una definición de la misma:

En muchas ocasiones, en sentido general, utilizamos este término para referirnos al creciente grado de relaciones que mantienen las diferentes regiones y países del mundo, en particular en las áreas comerciales, financieras, culturales y de comunicación.

En un sentido más técnico, la globalización se define como una proceso por el que la creciente comunicación e interdependencia entre los distintos países del mundo unifica mercados, sociedades y culturas.

Existe consenso a la hora de afirmar que una de las consecuencias fundamentales de la globalización es el mayor nivel de integración entre las diferentes regiones del mundo y la repercusión de ese nivel de integración en las nuevas condiciones sociales y económicas de los países. Sin embargo, donde se manifiestan notables discrepancias es respecto a los mecanismos y principios que rigen esos cambios.

Como todo proceso, la globalización es un fenómeno complejo, por lo que no cabe decir que ha sido planificado en exclusiva por un grupo o institución. Ahora bien, tampoco se puede volver la espalda a la realidad y negar el papel de las multinacionales y de los gobiernos de las grandes potencias para que la globalización discurra por determinados cauces, fundamentalmente en lo económico. 
En su dimensión económica, la globalización ha sido entendida como una nueva fase de expansión del sistema capitalista que se caracteriza por la apertura de los sistemas económicos nacionales, por el aumento del comercio internacional, por la expansión de los mercados financieros, por la reorganización espacial de la producción, por la búsqueda permanente de ventajas comparativas y de la competitividad, y por la aparición de empleos más precarios, con descenso del nivel de remuneraciones.

$Y$ es que, en efecto, este contexto de capitalismo globalizado, es el adecuado para potenciar, gracias a la expansión y al uso intensivo de la tecnología, la desregulación de los mercados y la flexibilidad de los modos de producción, que es lo que conviene a las economías de los países hegemónicos y a sus empresas transnacionales.

Ello ha motivado que se vea la globalización como la nueva cara del imperialismo y se ponga en duda la idea de globalización asociada a un proceso positivo de integración de las economías mundiales, dirigido al aumento del bienestar social y a la mejor asignación de los recursos económicos. Prevalece la idea de que el fenómeno de la globalización en ningún momento fue concebido como un modelo de desarrollo económico, sino como un marco para regular las relaciones económicas internacionales entre los países industrializados.

En la actualidad, la producción de bienes y servicios está globalizada en torno a redes productivas de 53.000 empresas multinacionales y en alrededor de 41.000 empresas auxiliares. Estas redes emplean a tan «sólo» unos 200 millones de trabajadores (de los 3.000 millones de gentes que trabajan para vivir en el planeta), pero en ellas se genera el $30 \%$ del producto bruto global y las dos terceras partes del comercio mundial (Fuente: M. Castells, artículo en el periódico El País, 24-07-2001).

Llegado a este punto y con el objeto de enlazar posteriormente con el papel del Cooperativismo en el contexto actual, me interesa destacar dos efectos negativos de la creciente implantación de las grandes corporaciones en la era de la globalización:

1. Desplazamiento de las empresas por el mundo hacia donde la mano de obra sea más barata, buscando incrementar su nivel de productividad a través de la explotación del factor trabajo. Con ello, se pretende quebrantar la legislación laboral e implantar de nuevo la figura del trabajador de usar y tirar, disponible en el momento justo y por el tiempo necesario. 
2. Huida de los beneficios económicos de los lugares de producción, con su consiguiente concentración en determinadas áreas geográficas hegemónicas, principalmente, la Unión Europea, los Estados Unidos y Japón.

\section{La alternativa cooperativa: una explicación del ideario cooperativo a través de sus principios}

Frente a ese modelo de empresa, se nos presenta la «Alternativa Cooperativa» (expresión tomada del título del libro del profesor J. Divar, publicado en Barcelona en 1985), que nos conduce a un escenario opuesto al anterior. Utilizando la frase del P. J.M. Arizmendiarrieta a un modelo de «Empresa para el Hombre».

Esta empresa, condicionada por las exigencias de un mercado cada vez más competitivo, se ha visto obligada a crear un tipo societario que, en lo externo, se acerca a una organización tipo sociedad lucrativa, aunque, en realidad, se diferencia de éstas en consideraciones internas; en que fija sus normas sociojurídicas en unos principios de democratización económica y solidaridad social.

Para explicar el ideario de la Alternativa Cooperativa es necesario exponer la «Declaración de la Alianza Cooperativa Internacional sobre Identidad Cooperativa», adoptada en el Congreso de Manchester en 1995 para conmemorar el centenario de la Alianza Cooperativa Internacional, y el Informe de la propia Alianza (ambos documentos están publicados en el Anuario de Estudios Cooperativos de la Universidad de Deusto de 1995, pp. 73 y ss.), que explica las razones que han llevado a la adopción de la Declaración sobre Identidad Cooperativa.

En la Declaración, que explica con claridad la esencia del movimiento cooperativo, pueden distinguirse tres partes: una definición de Cooperativa, una lista de los valores clave del Cooperativismo y una redefinición de los principios cooperativos para ajustarlos a las nuevas realidades sociales:

1. ' Definición de Cooperativa: La Declaración define la cooperativa como «una asociación autónoma de personas que se han unido de forma voluntaria para satisfacer sus necesidades económicas, sociales y culturales en común mediante una empresa de propiedad conjunta y de gestión democrática». 
Esta definición no es una definición jurídica en sentido estricto, pretende ser una declaración de mínimos, útil para la redacción de las legislaciones, la educación de los socios y la preparación de libros de texto. A mi juicio, debe resaltarse la referencia a que los socios de una cooperativa satisfacen sus necesidades económicas, sociales y culturales en común. En este punto, en el Informe de la Alianza Cooperativa Internacional se señala que esta parte de la definición subraya que las cooperativas están organizadas por los socios para su beneficio individual y mutuo; que normalmente las cooperativas deben funcionar en el mercado y, por lo tanto, deben ser conducidas eficaz y prudentemente para alcanzar fines económicos y también metas sociales y culturales. Igualmente, es especialmente significativa la conceptuación de la cooperativa como empresa de propiedad conjunta y de gestión democrática. Estas dos características son las que deben tomarse como referencia para distinguir las cooperativas de otros tipos de organizaciones, especialmente las empresas controladas por el capital o las organizaciones controladas por el gobierno.

2. ${ }^{\text {a }}$ Valores Cooperativos: Sobre los valores cooperativos, la Declaración de la Alianza de 1995 dice que las cooperativas están basadas en los valores de la autoayuda, la autorresponsabilidad, la democracia, la igualdad, la equidad y la solidaridad. Además, destaca que, siguiendo la tradición de sus fundadores, los socios cooperativos - sin descartar que puedan encontrarse en otro tipo de organizacioneshacen suyos los valores éticos de la honestidad, la transparencia, la responsabilidad y la vocación sociales.

El movimiento cooperativo tiene una historia intelectual larga y distinguida. En el curso de la misma ha habido grandes aportaciones de diferentes teóricos de varias partes del mundo (una referencia al tema puede verse en Drimer A. y B., Las Cooperativas. Fundamento, historia y doctrina, Buenos Aires, 1981, pp. 267 y ss.). Por eso, conseguir un consenso sobre los valores cooperativos esenciales ha sido una tarea compleja. En 1990 y 1992, bajo la dirección del Sr. Sven Böök de Suecia, miembros de la $\mathrm{ACl}$ e investigadores independientes se dedicaron a una extensa discusión sobre la naturaleza de los valores cooperativos. Los resultados de ese estudio están recogidos en el libro Los Valores Cooperativos en un mundo en cambio, escrito por Böök y publicado por la ACI. Ese libro, junto con Principios Cooperativos: Hoy y mañana, escrito por W. P. Watkins, constituyen los pilares sobre los que se asentó la Declaración sobre Identidad Cooperativa. 
Los valores específicos de las sociedades cooperativas son los recogidos en la primera frase sobre los valores de la Declaración de Manchester: "Las cooperativas están basadas en los valores de la autoayuda, la autorresponsabilidad, la democracia, la igualdad, la equidad y la solidaridad». Para explicar cada uno de ellos, en el referido Informe de la $\mathrm{ACl}$ se apunta lo siguiente:

La «autoayuda» se basa en la creencia de que todo el mundo puede y debería esforzarse por controlar su propio destino (la frase ya fue empleada por M. Coady para titular en 1964 uno de sus libros, subtitulado: una experiencia de educación de masas). Los cooperativistas creen, sin embargo, que el desarrollo individual pleno solamente puede producirse en asociación con los demás. Como individuo, uno está limitado en lo que puede intentar hacer, y en lo que puede conseguir. A través de la acción conjunta y de la responsabilidad mutua, se puede conseguir más, especialmente aumentando la influencia colectiva de uno en el mercado y ante los gobiernos.

Los individuos también se desarrollan como personas mediante la acción cooperativa debido a las habilidades que adquieren al facilitar el crecimiento de su cooperativa, al conocimiento que consiguen de sus compañeros, a las nuevas percepciones que alcanzan sobre la sociedad más amplia de la que forman parte. En este sentido, las cooperativas son instituciones que fomentan la educación y desarrollo continuos de todos los implicados.

La «autorresponsabilidad» significa que los socios asumen la responsabilidad de la fundación y de la vida de la cooperativa. Además, son los responsables de promover su cooperativa entre sus familias, amigos y conocidos. Este valor cooperativo también significa que los socios son responsables de asegurarse que su cooperativa permanece independiente de otras organizaciones públicas o privadas.

Las cooperativas están basadas en la igualdad, constituyendo su unidad básica el socio. Esta fundamentación en la persona humana es una de las principales características que distingue a una cooperativa de las empresas orientadas principalmente en beneficio del capital. Los socios tienen el derecho de participación, el derecho de ser informados, el derecho de ser escuchados y el derecho de estar involucrados en la toma de decisiones. Los socios deberían estar asociados de la forma más igualitaria posible, lo que es a veces una tarea difícil en las grandes cooperativas o en federaciones de cooperativas. De hecho, la preocupación para conseguir y mantener la igualdad es un 
reto continuo para todas las cooperativas. En última instancia, se trata tanto de una forma de intentar hacer los negocios como de una pura y simple declaración de principios.

También conseguir la equidad dentro de la cooperativa es un reto continuo. La equidad se refiere a cómo se trata a los socios en una cooperativa. Deben ser tratados equitativamente en cuanto a la forma de recompensar su participación en la cooperativa, normalmente mediante retornos, asignaciones a reservas de capital en su nombre, o reducciones en precios. La equidad es importante para las cooperativas, porque es la forma en la que intentan distribuir ganancias o riqueza en base a la contribución y no a la especulación.

La «solidaridad» asegura en las cooperativas que la acción derivada de esta organización no es simplemente una forma disfrazada de interés personal ilimitado. Una cooperativa es más que una asociación de socios; es también una colectividad. Los socios tienen la responsabilidad de asegurar que todos ellos son tratados de la forma más justa posible.

Además, la «solidaridad» significa aspiración a crear un movimiento cooperativo unido, local, nacional, regional e internacionalmente. Los cooperativistas aceptan que hay un punto común entre todas las cooperativas sin importar sus diferentes fines y sus diferentes contextos.

Finalmente, hay que resaltar que la solidaridad es la misma causa y consecuencia de la autoayuda y la ayuda mutua, dos de los conceptos fundamentales de la filosofía cooperativa; conceptos que constituyen la base para diferenciar las cooperativas de otras formas de organización económica.

3. ${ }^{a}$ Principios Cooperativos: Los principios cooperativos son definidos por la Declaración como pautas mediante las cuales las cooperativas ponen en práctica sus valores. Es indudable que son mandamientos que deben ser seguidos por las cooperativas, aunque, como acertadamente destaca el Informe de la Alianza, no es suficiente preguntar si una cooperativa está siguiendo al pie de la letra un principio, es igualmente importante saber si está siguiendo su espíritu. Si la visión que proporciona cada principio, individual y colectivamente, está arraigada en las actividades diarias de la cooperativa. Además, no pueden considerarse independientes: los principios están unidos sutilmente. Cuando se pasa uno por alto, todos se resienten. No hay que 
evaluar las cooperativas exclusivamente sobre la base de un principio dado, más bien, deben ser evaluadas en base a cómo se adhieren a los principios en su totalidad.

Hay siete principios listados en la Declaración de 1995: Adhesión Voluntaria y Abierta; Gestión Democrática por parte de los socios; Participación Económica por parte de los socios, Autonomía e Independencia; Educación, Formación e Información; Cooperación entre Cooperativas e Interés por la Comunidad. Los tres primeros principios se dirigen a la dinámica interna típica de cualquier cooperativa. Los cuatros últimos se dirigen tanto al funcionamiento interno como a las relaciones externas de las cooperativas.

En la Declaración de 1995 los principios han sido formulados de la forma siguiente:

1. Adhesión Voluntaria y Abierta: "Las cooperativas son organizaciones voluntarias, abiertas a todas las personas capaces de utilizar sus servicios y dispuestas a aceptar las responsabilidades de ser socio, sin discriminación social, política, religiosa, racial o de sexo». Del primer principio merece especial atención la frase que afirma que las cooperativas están "abiertas a todas las personas capaces de utilizar sus servicios y dispuestas a aceptar las responsabilidades de ser socio, sin discriminación, política, religiosa, racial o de sexo». Esta declaración reafirma el compromiso de las cooperativas con el reconocimiento de la dignidad fundamental de todos los individuos.

2. 'Gestión Democrática por parte de los socios: «Las cooperativas son organizaciones gestionadas democráticamente por los socios, los cuales participan activamente en la fijación de sus políticas y en la toma de decisiones. Los hombres y las mujeres elegidos para representar y gestionar las cooperativas son responsables ante los socios. En las cooperativas de primer grado, los socios tienen iguales derechos de voto (un socio, un voto) y las cooperativas de otros grados están también organizadas de forma democrática». La regla para las cooperativas de primer grado es clara; en cambio, más dudas plantea la interpretación del último inciso. En el Informe de la Alianza se aclara que la regla para las votaciones en otros grados es abierta. Se considera que los propios movimientos cooperativos son los más capaces de definir lo que es democrático en una circunstancia dada. Incluso se reconoce que en muchas cooperativas de segundo y tercer grado, los sistemas de votación proporcional han sido adoptados para reflejar la diversidad de intereses, el número de socios en cooperativas asociadas 
y el compromiso entre las cooperativas involucradas. Ahora bien, también se señala que tales acuerdos deben revisados periódicamente y que es normalmente insatisfactorio si las cooperativas más pequeñas en tales situaciones tienen tan poca influencia que prácticamente se sienten privadas del derecho de voto.

3. Participación Económica de los socios: «Los socios contribuyen equitativamente al capital de sus cooperativas y lo gestionan de forma democrática. Por lo menos parte de ese capital debe ser propiedad común de la cooperativa. Normalmente, los socios reciben una compensación, si la hay, limitada sobre el capital entregado para adquirir la condición de socio. Los socios asignan los excedentes para todos o algunos de los siguientes fines: el desarrollo de su cooperativa, posiblemente mediante el establecimiento de reservas, parte de las cuales por lo menos serían indivisibles; el beneficio de los socios en proporción a sus operaciones con la cooperativa; y el apoyo de otras actividades aprobadas por los socios». Este principio describe tanto cómo participan los socios en el capital, como la forma en que deben distribuirse los excedentes. Es digna de ser resaltada la frase que señala que «los socios contribuyen equitativamente al capital de las cooperativas y lo gestionan de forma democrática», dado que, por una parte, hace hincapié en la necesidad de que los socios aporten capital a su cooperativa y, por otra, permite que las diferentes legislaciones exijan que cada socio aporte, sin que ello tenga trascendencia en el proceso de adopción de decisiones, cantidades distintas, según su capacidad económica. En la asignación de excedentes resulta sorprendente la flexibilidad: "Los socios asignan los excedentes para todos o alguno de los siguientes fines ...». Sin embargo, en un sistema legal como el nuestro en el que se parte del carácter societario de la cooperativa, resulta impensable que las distintas normas no exijan la constitución de un fondo de reserva obligatorio.

4. ${ }^{\circ}$ Autonomía e Independencia: "Las cooperativas son organizaciones autónomas de autoayuda, gestionadas por sus socios. Si firman acuerdos con otras organizaciones, incluidos los gobiernos, o si consiguen capital de fuentes externas, lo hacen en términos que aseguren el control democrático por parte de sus socios y mantengan su autonomía cooperativa». Este principio no se recogió explícitamente en la formulación de 1996. En ese momento, la ACl adoptó una posición más condescendiente para evitar la salida de la entidad internacional de los países de regímenes comunistas, dado que limitaban la autonomía e independencia de sus cooperativas. Ahora, tras la caída de tales 
regímenes, la $\mathrm{ACl}$ vuelve hacia la posición de 1937, época en la que consagró como uno de los principios la «neutralidad política y religiosa». Sin embargo, lo más novedoso en la formulación de este principio es la referencia a la firma de acuerdos «con otras organizaciones». Con ella se reconoce el hecho de que, en todo el mundo, cada vez más cooperativas están entrando en proyectos conjuntos con empresas del sector privado, aunque se señala la importancia de que éstas mantengan la libertad de controlar su propio destino futuro al negociar tales acuerdos.

5. Educación, Formación e Información: "Las cooperativas proporcionan educación y formación a los socios, a los representantes elegidos, a los directivos y a los empleados para que puedan contribuir de forma eficaz al desarrollo de sus cooperativas. Informan al gran público, especialmente a los jóvenes y a los lideres de opinión, de la naturaleza y beneficios de la cooperación». El movimiento cooperativo tiene un compromiso claro y antiguo con la educación de los socios. En este sentido, la Declaración de 1995 señala que los fondos cooperativos destinados a este fin deben dedicarse a la educación —dirigida a la comprensión de la complejidad y riqueza del pensamiento y acción cooperativos- y a la formación - dirigida a la capacitación profesional- de todos lo que están implicados en las cooperativas, no sólo de los socios, y a la información al gran público - especialmente a los jóvenes y a los lideres de opinión- de la naturaleza y beneficios de la cooperación. Se realiza especial hincapié en esta última actividad, descuidada en las últimas décadas por muchas cooperativas, que tiene gran importancia para su desarrollo futuro, ya que nadie aprecia ni apoya lo que no entiende (sobre la utilidad de la labor de los Centros de Estudios Cooperativos, puede verse lo apuntado por D. Benavides, en Evolución del Pensamiento Cooperativista, Buenos Aires, 1987, pp. 138 y ss.).

6. Cooperación entre cooperativas: "Las cooperativas sirven a sus socios lo más eficazmente posible y fortalecen el movimiento cooperativo trabajando conjuntamente mediante estructuras locales, nacionales, regionales, e internacionales». Para conseguir esos objetivos - servir eficazmente a sus socios y fortalecer el movimiento cooperativo- es necesario crear estructuras. Por ello surgen las asociaciones, federaciones, confederaciones y entes interregionales e internacionales cuya cúspide es la $\mathrm{ACl}$.

7. ${ }^{\circ}$ Interés por la Comunidad: "Las cooperativas trabajan para conseguir el desarrollo sostenible de sus comunidades mediante políti- 
cas aprobadas por sus socios». En 1966, al enunciar el sexto principio de cooperación entre cooperativas, se señaló como objetivo "servir mejor a los intereses de sus miembros y de la comunidad». En 1995 se concede mayor importancia a este objetivo, atribuyendo a la «preocupación por la comunidad» el carácter de principio. Sin duda, se reconoce que las cooperativas son organizaciones que existen principalmente para el beneficio de sus socios, aunque dada la vinculación de las cooperativas a sus comunidades - a diferencia de las sociedades capitalistas que pueden llegar o irse según las condiciones coyunturales que se presenten para su desarrollo- los socios no pueden obviar el fuerte compromiso social de éstas, que, independientemente de las condiciones coyunturales, deben dirigir su labor hacia el aumento del bienestar social, haciendo de la proyección y la acción hacia la comunidad, característica cooperativa.

Finalmente, cabe destacar, a modo de conclusión, que los principios cooperativos, derivados de los valores, conforman las estructuras y determinan las actitudes que proporcionan las características propias al movimiento. Son principios prácticos en sí mismos, creados tanto por la experiencia de generaciones como por el pensamiento filosófico, mediante las cuales los cooperativistas se esfuerzan por desarrollar sus organizaciones cooperativas. Se trata de pautas flexibles mediante las que se delimita la naturaleza democrática de sus instituciones, el papel de los diferentes partícipes y la forma de distribuir los excedentes creados. En definitiva, los principios determinan las cualidades esenciales que hacen que las cooperativas sean diferentes a los otros tipos de empresa y que el movimiento cooperativo sea valioso.

\section{La efectividad de la democracia participativa en las cooperativas como elemento clave para el éxito del movimiento}

La vigencia del principio de la democracia participativa - que no es otra cosa que la involucración de los socios en la toma de decisiones de la sociedad - ha constituido siempre un permanente desafío para las cooperativas, aunque aún más en el momento actual en el que se analiza el papel de las cooperativas dentro de una economía globalizada y muy competitiva. Es cierto que muchas cooperativas existentes en los países industrializados han imitado los métodos de los negocios convencionales para afrontar la competencia, socavando con ello el fundamento que separa a las cooperativas de las empresas 
capitalistas. Sin embargo, como ha señalado Masayuki Yamagishi (La democracia participativa en las cooperativas: cómo dar significado a la participación, Buenos Aires, 1995, p. ii), no es exagerado decir que el destino de las cooperativas en el siglo veintiuno dependerá de si pueden o no asegurar su supremacía con respecto a las corporaciones privadas al movilizar su potencial humano: "La energía latente que duerme en las legiones de socios y empleados de las cooperativas». El sistema para mantener ese enorme potencial humano en una eficiente y efectiva acción es la democracia participativa.

En el siglo veinte se han mejorado las condiciones de vida. El desarrollo tecnológico ha contribuido a ello de manera notable, aunque ese desarrollo también ha generado efectos colaterales adversos; fundamentalmente, la distribución desigual de los ingresos y la degradación ambiental. Esos hechos han llevado a aumentar la conciencia de que los viejos modelos de desarrollo son insostenibles. Y ahí, en ese contexto, el papel de las cooperativas debe dirigirse a constituir un nuevo orden social. Las cooperativas deben aparecer como el vehículo que contribuya a la creación de una nueva sociedad orientada hacia los ciudadanos. No se trata de un cambio revolucionario sino de una evolución motivada por el convencimiento ciudadano de que las prácticas cooperativas constituyen el mejor modelo de desarrollo. En palabras de J. Divar (recogidas de Globalización y democracia, Madrid, 2005, p. 77), el Cooperativismo constituye la alternativa para conseguir «un aterrizaje suave en un nuevo orden económico, cuyos caracteres fundamentales habrían de ser los de participación, solidaridad y cooperación».

Sin embargo, para conseguir la eficiencia del sistema cooperativo es necesaria una auténtica estructura democrática participativa en las que sus miembros vean satisfechas sus necesidades y reflejadas sus visiones. La democracia participativa efectiva y real, no sólo no dificultará el éxito de los negocios sino que puede mejorarlo. Además, los valores del sistema cooperativo son eficaces para alcanzar, junto al económico, otros objetivos de orden personal como la autoestima, la autorrealización o incluso para encontrar sentido a la existencia. En nuestras sociedades, la condición de identidad colectiva plantea más problemas que la condición de necesidad. El individualismo reinante, la desaparición de los vínculos sociales y el debilitamiento de las bases tradicionales (la religión, la relaciones vecinales, el sindicalismo etc.) actúan contra esa identidad colectiva. En ese contexto, el ideario cooperativo puede marcar las pautas de un estilo de vida satisfactorio y 
pleno (sobre esta cuestión, puede verse H. Münkner, «Valores cooperativos básicos para llenar un vacío conceptual con especial atención a Africa», en Anuario de estudios Cooperativos de la Universidad de Deusto, 1995, pp. 293 y ss.).

El problema es cómo dar significado a la participación. En este punto, debe partirse de, al menos, dos premisas esenciales.

1. ${ }^{\text {a }}$ La democracia participativa debe integrarse en las actividades cooperativas.

2. ${ }^{\text {a }}$ La democracia participativa no se fija de una vez, sino que se desarrolla a medida que se originan cambios en la sociedad o en las condiciones de los negocios.

A modo de orientación, vamos a hacer referencia al Proyecto Conjunto Internacional sobre Democracia Cooperativa (publicado bajo el título: La democracia participativa en las cooperativas, ya cit.) realizado por un equipo formado por investigadores de Canadá, Japón, Suecia, Gran Bretaña e Italia y en el que aparecen nombres tan prestigiosos como el del Dr. Ian MacPeherson, el del Dr. Sven Böök o el del Dr. Alf Carlsson. En el Informe Final del Proyecto, pensado para cooperativas de consumo, se indica que para hacer efectiva la democracia participativa es necesario:

1. a Aumentar la participación de los socios.

2. ${ }^{a}$ Fomentar la relación entre los socios y la gerencia.

3. ${ }^{a}$ Realizar innovaciones en la estructura organizacional.

4. aumentar la relación con la participación de los socios.

5. ${ }^{a}$ Imponer responsabilidad económica y social.

A continuación se señalan ejemplos concretos de posibles actuaciones en cada una de las cinco áreas señaladas. Desde una perspectiva global, sin especificar áreas concretas, me parece interesante resaltar las actuaciones siguientes:

- Conseguir reuniones generales anuales más participativas.

- Ofrecer espacios para celebrar reuniones y actividades no relacionadas directamente con los negocios de la cooperativa.

-Establecer iniciativas vinculadas con intereses específicos de los socios.

- Impartir programas dirigidos a la educación cooperativa.

- Hacer participar a los empleados en círculos de calidad.

- Cambiar la imagen del establecimiento de la cooperativa y adaptar los rótulos y marcas a los nuevos tiempos. 
-Fomentar la asociación entre cooperativas y comunidades locales.

- Presentar auditorías sociales para mostrar las contribuciones de las cooperativas a sus socios.

—Fomentar, incluso imponer, la comunicación entre la gerencia y los socios.

En sus conclusiones, el Informe referido señala que no hay nada místico en el compromiso y lealtad de los socios ni tampoco éstas son cualidades de la personalidad. El compromiso y la lealtad se logran a través del trabajo cotidiano de toda organización y el modo en el que los socios evalúan cómo son tratados. Todos los negocios dependen de algún tipo de compromiso y lealtad. Las cooperativas tienen acceso a una variedad de formas para aumentar la lealtad y el compromiso de sus socios, incluyendo uno que los otros negocios no pueden ofrecer: la promesa de un contexto democrático y una variedad de oportunidades de participación en la cooperativa.

\section{Inserción social y Cooperativismo}

El Cooperativismo ha nacido y se ha desarrollado entre las clases trabajadoras explotadas que luchaban por mejorar sus condiciones precarias de vida. Es indiscutible que la cooperación es «hija de la necesidad» (la expresión se ha atribuido a H. Desroche, Le projet coopératif, Paris, 1976). Por tanto, a nadie debe sorprender que la nueva economía social deba atender también las nuevas necesidades insatisfechas por el mercado o por la intervención pública.

En este momento, el Cooperativismo debe procurar la inserción por el trabajo de personas de difícil colocación: desempleados de larga duración, personas con antecedentes penales, trabajadores con bajo nivel de escolarización, inmigrantes etc.

Precisamente, sobre este tema se ha realizado un importante estudio publicado por CIRIEC-ESPAÑA, en 1997, bajo el título «Inserción y Nueva Economía Social». El estudio, dirigido por J. Defourny, L. Favreau y J.L. Laville, contiene nueve artículos en los que se analiza el papel que desarrolla la economía social entre el colectivo de personas con necesidades en Francia, Bélgica, Italia, Alemania, Canadá (Quebec), Suecia, Reino Unido, España y Austria.

Entre ellos, merece ser destacado el caso italiano: en Italia la aprobación de una ley específica en 1991 ha acelerado el desarrollo de la 
cooperación social en general y de las cooperativas dedicadas a la inserción de personas desfavorecidas en particular.

Y muy especialmente, el caso de Suecia. En este país, a principios de los 80, como ya no se creía en los intentos de «remediar» los problemas rurales mediante la subvención de la migración de los parados hacia zonas urbanas donde había trabajo, o bien en la implantación de empresas en las zonas rurales en donde se encontraban los parados, surgió el interés por la idea de un desarrollo local «auténtico».

Para ello se crearon, a partir de iniciativas de entes locales, no de organizaciones nacionales, los Ilamados Centros o Agencias de Desarrollo Cooperativo (LKU), que se han convertido en la pieza clave del modelo sueco. Las LKU se dedican, con financiación de los poderes públicos locales y de las organizaciones asociadas, al fomento del desarrollo cooperativo (no a la gestión directa), mediante actividades de comunicación, de asesoramiento y de formación sobre la empresa cooperativa.

Aunque estas agencias no se dedican de forma explícita a la lucha contra la exclusión y no aplican medidas únicamente a favor de los grupos excluidos, sus servicios han considerado siempre que estas personas constituían un grupo importante de trabajo.

Desde su creación, las LKU han jugado un papel activo en el desarrollo local de zonas rurales, en las afueras de las grandes ciudades con un tanto por cien elevado de inmigración y entre los grupos de jóvenes. Hay un dato revelador: en 1992, las LKU apoyaron la constitución de 300 nuevas cooperativas, que crearon unos 1.300 puestos de trabajo, con un coste de creación de empleo tres veces inferior a la media (para más datos puede verse, Y. Stryjan y F. Wijkström, "Las Agencias de desarrollo cooperativo como método paliativo de los recientes fallos del sistema», en Inserción y Nueva Economía Social, cit.).

Sobre la base de lo anterior, debe concluirse que, sin perjuicio de que continúen con sus prácticas de fomento del empleo en las empresas tradicionales y con sus políticas de fomento del trabajo independiente, los poderes públicos no deben olvidar que el apoyo a asociaciones dirigidas a fomentar una economía solidaria tiene utilidad social y también utilidad económica cuantificable objetivamente en atención al coste de la creación de empleo. 